\title{
Isolation and characterization of novel reassortant H6N1 avian influenza viruses from chickens in Eastern China
}

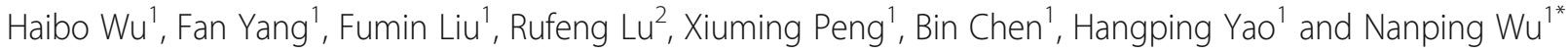

\begin{abstract}
Background: The H6N1 subtype of avian influenza viruses (AIVs) can infect people with an influenza-like illness; the H6N1 viruses possess the ability for zoonotic transmission from avians into mammals, and possibly pose a threat to human health.

Methods: In 2017, live poultry markets (LPMs) in Zhejiang Province were surveyed for AlVs. To better understand the genetic relationships between these strains from Eastern China and other AlVs, all gene segments of these strains were sequenced and compared with sequences available in GenBank. In this study, we analyzed the receptor-binding specificity, antigenic characteristics, and pathogenicity of these two H6N1 viruses.

Results: In 2017, two H6N1 AIVs were isolated from chickens during surveillance for Alvs in LPMs in Eastern China. Phylogenetic analysis showed that these strains shared genetic characteristics from $\mathrm{H} 6, \mathrm{H} 10, \mathrm{H} 1$, and $\mathrm{H} 4$ AlVs found in ducks and wild birds in East Asia. These AIV strains were able to replicate in mice without prior adaptation.

Conclusions: In this study, we report the discovery of new strains of H6N1 viruses from chickens with novel gene reassortments. Our results suggest that these chickens play an important role generating novel reassortments in AlVs, and emphasize the need for continued surveillance of AIV strains circulating in poultry.
\end{abstract}

Keywords: Avian influenza viruses, Subtype H6N1, Chickens, Reassortant, Eastern China

\section{Background}

Influenza A viruses are classified into 18 hemagglutinin (HA) and 11 neuraminidase (NA) subtypes, based on the antigenic properties of the HA and NA glycoproteins $[1,2]$. Aquatic birds are considered a natural reservoir for avian influenza virus (AIV) [3]. Birds infected with AIVs, including poultry and wild birds, do not usually display clinical symptoms; however, they provide an environment for the reassortment of low pathogenic AIVs, which can serve as progenitors of highly pathogenic AIVs [4, 5]. The adaptation of AIVs to receptors in poultry can enhance the potential for avian-to-human transmission of AIVs; populations of terrestrial poultry

\footnotetext{
* Correspondence: flwnp@zju.edu.cn

${ }^{1}$ State Key Laboratory for Diagnosis and Treatment of Infectious Diseases, Collaborative Innovation Center for Diagnosis and Treatment of Infectious Diseases, the First Affiliated Hospital, School of Medicine, Zhejiang University, 79 Qingchun Road, Zhejiang 310003, Hangzhou, China

Full list of author information is available at the end of the article
}

species, especially chickens and quails, play an important role in expanding the host of influenza viruses [6-8].

The H6 subtypes of AIVs were first isolated from a turkey in 1965 in the United States and were subsequently identified in wild migratory birds [9-13]. H6 AIVs have infected ducks and chickens, and circulate in live poultry markets (LPMs) in China [14-19]. In China, serological evidence has demonstrated human infection with H6 AIVs, as well as infection in other mammals [20]. Previous studies in Taiwan showed that the H6N1 subtype of low pathogenic AIVs can infect humans with an influenza-like illness [21, 22]. In 2014, an H6N1 virus was isolated from dogs in Taiwan; molecular analysis indicated that this isolate was closely related to the human H6N1 virus circulating in Taiwan, and harbored the E627K substitution in the polymerase basic protein 2 (PB2) [23]. In addition, the human-infecting H6N1 virus possesses the ability to cross the species barrier to infect other mammals $[23,24]$, these results also indicated that 
E190V and G228S mutations of HA are important to acquire the human receptor-binding capacity, and the P186L mutation of HA could reduce the avian receptor-binding capacity [25]. The $\mathrm{H} 6$ viruses possess similar internal genes to the human $\mathrm{H} 5 \mathrm{~N} 1$ and $\mathrm{H} 9 \mathrm{~N} 2$ viruses $[17,26]$. These data indicate that the H6 AIVs pose a threat to human health, and emphasize the need for continued surveillance of the H6 AIVs circulating in poultry.

In 2017, during surveillance of poultry for AIVs in Zhejiang Province, Eastern China, two H6N1 viruses, named A/chicken/Zhejiang/1664/2017(H6N1) and A/chicken/ Zhejiang/1667/2017 (H6N1) (ZJ-1664 and ZJ-1667, respectively), were isolated from apparently healthy chickens. To better understand the genetic relationships between these strains from Eastern China and other AIVs, all gene segments of these strains were sequenced and compared with sequences available in GenBank. These findings indicate that continued surveillance of H6N1 AIVs in poultry should be used as an early warning system for potential avian influenza outbreaks.

\section{Methods}

\section{Ethics statement}

Female 6-week-old pathogen-free BALB/c mice were purchased from Shanghai Laboratory Animal Center, Chinese Academy of Sciences, Shanghai, China, and housed in filter-top cages. The animal studies in this research were conducted in accordance with guidelines of animal welfare of World Organization for Animal Health. The protocols for mouse and embryonated chicken egg experiments were approved by the Ethics Committee of the First Affiliated Hospital, School of Medicine, Zhejiang University (permit number. 2015-015).

\section{Virus isolation}

Cloacal swabs $(n=72)$ were collected from apparently healthy poultry in a LPM in Hangzhou, Zhejiang Province, Eastern China, on January 6, 2017. Each sample was inoculated into the allantoic cavities of 9-day-old specific pathogen-free embryonated eggs as described previously [27, 28]. After incubation at $37{ }^{\circ} \mathrm{C}$ for $72 \mathrm{~h}$, the allantoic fluid was harvested and viral titers were determined by hemagglutination assay using a standard method, as described previously [28].

\section{RNA extraction and PCR amplification}

RNA was extracted from HA-positive allantoic fluid samples using TRIzol (Life Technologies, USA) according to the manufacturer's instructions. Reverse transcription was performed using the Uni12 primer: 5'-AGCAAAAGC AGG-3'. Reverse transcriptase-polymerase chain reaction (RT-PCR) was conducted using a One-Step RNA PCR Kit (TaKaRa, China) as described previously [28]. All segments were amplified with previously described segment-specific primers [29]. The PCR products were purified using an Agarose Gel DNA Fragment Recovery Kit Ver. 2.0 (TaKaRa).

\section{Sequencing and phylogenetic analysis}

Amplified PCR fragments were sequenced using a Big Dye Terminator V.3.0 Cycle Sequencing Ready Reaction kit (ABI, Foster City, CA, USA) according to the manufacturer's instructions. All eight gene segments of the AIV field isolates were sequenced, including PB2, polymerase basic protein 1 (PB1), polymerase acidic protein (PA), HA, nucleocapsid protein (NP), NA, matrix protein $(\mathrm{M})$, and nonstructural protein (NS); sequences were compared with those from reference viruses. The classical reference viruses were selected based on previous reports $[14,18,26]$, and the reference sequences of the strains used in this study were obtained from the Influenza Virus Resource (https://www.ncbi.nlm.nih.gov/ genomes/FLU/Database/nph-select.cgi?go=database). Sequences were analyzed using BioEdit DNA software version 7.0.9.0. Phylogenetic trees were constructed using molecular evolutionary genetics analysis (MEGA) software version 6.0, applying the maximum likelihood method and the Tamura-Nei model with bootstrap analysis (1000 replicates) as described previously [28, 30]. The nucleotide sequences were deposited into GenBank under the accession numbers: MG063430-45.

\section{Prediction of glycosylation sites}

The NetNGlyc 1.0 server was used to predict potential $N$-linked glycosylation sites (defined as Asn-X-Ser/Thr, where $\mathrm{X}$ is any amino acid except Asp or Pro); a threshold value $>0.5$ for the average potential score suggests glycosylation [31, 32].

\section{Receptor-binding analysis}

The $\alpha$-2,3-specific sialidase-treated red blood cell (RBC) hemmaglutination assay is commonly employed to screen receptor specificity $[33,34]$. The receptor binding preference of the H6N1 AIVs was determined by performing hemagglutination assays on receptor-specific RBCs, including normal chicken RBCs (containing both $\alpha-2,6$ and $\alpha-2,3$ receptor), $\alpha-2,3$-specific sialidase-treated chicken RBCs (containing only $\alpha-2,6$ receptor after treatment), and sheep RBCs (mainly expressing $\alpha-2,3$ receptor). The $\alpha-2,6$ receptor-specific RBCs were prepared by treating chicken RBCs with $\alpha-2,3$ specific neuraminidase (NEB, $\mathrm{MA}$ ) as described previously [35-37]. Briefly, $10 \% \mathrm{RBC}$ in $1 \mathrm{~mL}$ were treated with $1000 \mathrm{IU} \alpha-2,3$-specific neuraminidase for $1 \mathrm{~h}$ at $37^{\circ} \mathrm{C}$, and washed three times with PBS. The final working solution for the hemagglutination assay was $0.5 \%$ RBCs in PBS. To determine the specific receptors on the treated and untreated RBCs, the avian 
influenza virus A/chicken/Zhejiang/329/2011(H9N2) and human influenza virus A/Puerto Rico/8/1934(H1N1) strains were included in the receptor binding assay as controls. Hemmaglutination assays were performed in $96^{\prime} \mathrm{V}$ '-well microtiter plates by incubating equal volumes $(50 \mu \mathrm{L})$ of a two-fold serial dilution of virus with each RBC type. The HA titer was defined as the reciprocal of the highest virus dilution resulting in the hemagglutination of RBCs.

\section{Antigenic analysis}

The antigenic characteristics of these H6N1 AIVs were analyzed with a hemagglutination inhibition (HI) test, as described previously [38]. Mouse antisera against A/ chicken/Zhejiang/727031/2014 (H6N2), A/duck/Zhejiang/727038/2014 (H6N2), A/chicken /Zhejiang/ 727001/2014 (H6N6), A/chicken/Zhejiang/727028/2014 (H6N6), A/chicken /Zhejiang/110102/2015 (H6N6), A/ chicken/Zhejiang/C1/2013(H9N2), and A/goose/Zhejiang/112071/2014(H5N1) were provided by our laboratory, the $\mathrm{H} 9 \mathrm{~N} 2$ and $\mathrm{H} 5 \mathrm{~N} 1$ viruses were included as controls. The mouse antisera used for HI assay have been treated by receptor destroying enzyme (RDE, Denka Seiken, Japan). These viruses were all recently isolated from LPMs in Zhejiang Province, China, as described previously $[18,19]$.

\section{Viral growth kinetics}

Confluent MDCK or A549 cells were infected with ZJ-1664 and ZJ-1667 strains at a multiplicity of infection (MOI) of 0.1, overlaid with serum-free DMEM containing $2 \mathrm{mg} / \mathrm{mL}$ TPCK-trypsin (Sigma-Aldrich, USA) and incubated at $37{ }^{\circ} \mathrm{C}$ as described previously [39-41]. Cell supernatants were harvested every $12 \mathrm{~h}$ until $72 \mathrm{~h}$ postinoculation and titrated in embryonated chicken eggs by the Reed and Muench method [42].

\section{Animal studies}

To evaluate the replicative ability of the ZJ-1664 and ZJ-1667 strains in a mammalian host, fifteen 6-week-old female BALB/c mice were infected intranasally with $10^{6.0}$ EID50 per $1 \mathrm{ml}$ of each virus; three mice were sacrificed at 3 , 6, and 9 days post-inoculation. Lungs, brains, hearts, livers, kidneys, and spleens were collected for viral titer analysis in embryonated chicken eggs by the method of Reed and Muench [42]. The survival of the six remaining mice was observed for 14 days following inoculation.

\section{Histology and immunohistology of mouse lung sections}

Lung tissues from virus-inoculated mice were fixed in $10 \%$ neutral buffered formalin for at least $24 \mathrm{~h}$ before processing. The tissues were embedded in paraffin by standard tissue processing procedures. Sections "Discussion" $\mu \mathrm{m}$ thick were cut and fixed on glass slides.
Standard hematoxylin and eosin (H\&E) staining was carried out. Immunohistochemical staining to detect nucleoprotein antigens in the lungs was performed using a monoclonal antibody against the influenza A virus nucleoprotein (1:100 dilution). The sections were washed 3 times with PBS and then incubated with HRP-conjugated goat anti-mouse secondary antibody (1:3000 dilutions, Sigma). The sections were developed with 3-3' diaminobenzidine and examined with a light microscope, as described previously [43].

\section{Results}

\section{Virus isolation}

Three strains of AIVs were isolated from 72 cloacal swab samples collected from chickens in a LPM in the Yuhang district of Hangzhou City, the capital of Zhejiang Province, including one $\mathrm{H} 9 \mathrm{~N} 2$ and two H6N1 strains, ZJ-1664 and ZJ-1667.

\section{Phylogenetic analysis of the ZJ-1664 and ZJ-1667 H6N1 strains}

Phylogenetic analysis of all eight viral segments, PB2, PB1, PA, HA, NP, NA, M, and NS, showed that the ZJ-1664 and ZJ-1667 strains clustered in the AIV Eurasian lineage, Fig. 1. According to the HA genes, the H6 viruses from China are divided into three lineages: group I, group II (including W312-like), and group III [14, 18, 26]. Phylogenetic analysis of the HA genes from the ZJ-1664 and ZJ-1667 isolates indicated that these viruses were closely related to the group III viruses that circulated in Eurasian regions from 2009 to 2015, represented by the A/duck/ Hunan/573/2002 (H6N2) strain. The phylogeny of the HA genes also indicated that these viruses have a different lineage from the H6N1 virus responsible for human infection in Taiwan in 2013 [21]. We previously reported that the HA genes of H6 AIVs found in the Zhejiang Province (H6N2 and H6N6) belong to the group II viruses, represented by the A/wild duck/Shantou/2853/2003 (H6N2) strain $[18,19]$. These results suggest that at least two different genetic groups of the H6 viruses have spread through the Zhejiang Province in recent years.

Regarding the phylogeny of the NA gene, the ZJ-1664 and ZJ-1667 H6N1 viruses were most closely related to AIVs found in wild birds in Asia between 2014 and 2016. The sequence homologies of the HA and HA genes from the ZJ-1664 and ZJ-1667 strains were similar to the AIV reference strains, and the ZJ-1664 isolate was selected for in depth analysis. The percent sequence homology for each gene segment from ZJ-1664 compared to the closest genetic relative is shown in Table 1.

Homologous comparison to the GenBank reference database using BLAST showed that the HA and NA genes from ZJ-1664 had the highest similarity to the HA and NA genes from A/duck/Hubei/ZYSYG15/2015 


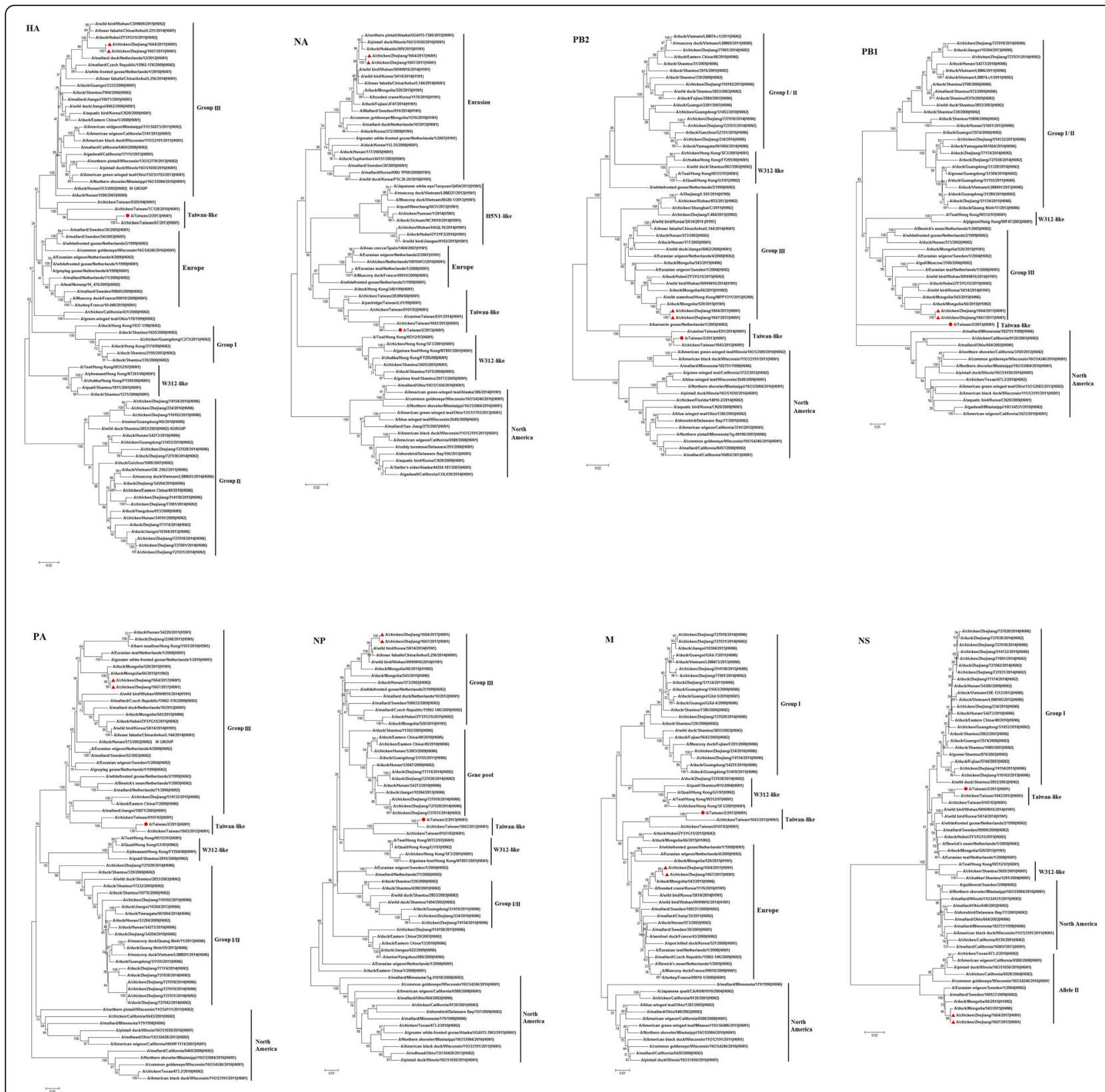

Fig. 1 Phylogenetic trees of HA (positions 1-1701), NA (positions 1-1410), PB2 (positions 1-2280), PB1 (positions 1-2274), PA (positions 1-2151), NP (positions 1-1497), M (positions 1-982), and NS (positions 1-838) segments from the novel reassortant H6N1 avian influenza viruses, ZJ-1664 and ZJ-1667. The tree was created by the maximum likelihood method and bootstrapped with 1000 replicates using the MEGA6 software version 6.0. The $\mathrm{H} 6 \mathrm{~N} 1$ viruses characterized are indicated by a triangle in red, and the H6N1 influenza virus responsible for human infection in 2013 is indicated by a dot in red. The scale bar represents the distance unit between sequence pairs

(H6N2) and A/wild bird/Wuhan/WHHN16/2014 (H1N1) strains, respectively. The PB2, PB1, PA, NP, M, and NS genes from ZJ-1664 shared the highest similarity with $\mathrm{H} 1$, $\mathrm{H} 10$, and $\mathrm{H} 4$ isolates, which were isolated from birds throughout Eastern Asia between 2014 and 2015 (Fig. 1, Table 1). Previous reports showed that the HA genes of H6 AIVs (including H6N1, H6N2, H6N5, H6N6, and H6N8) were cocirculated in domestic ducks in Eastern
China, and these $\mathrm{H} 6$ viruses all underwent frequent reassortment with multiple virus subtypes $[15,16,18,19]$. Based on the phylogenetic and homology analyses, ZJ-1664 is a result of viral reassortment from H6, H1, H10, and H4 AIV subtypes from poultry and wild bird in Eastern Asia (Fig. 2). These results are also indicative of the active evolution of H6 AIVs in Eastern China. 
Table 1 Sequence homology of the whole genome of the ZJ-1664 H6N1 avian influenza virus compared to influenza virus nucleotide sequences available in the GenBank database

\begin{tabular}{|c|c|c|c|c|c|}
\hline Segment & Position & $\begin{array}{l}\text { Virus with the highest percentage of } \\
\text { nucleotide identity }\end{array}$ & $\begin{array}{l}\text { Genbank accession } \\
\text { number }\end{array}$ & $\begin{array}{l}\text { Homology } \\
(\%)\end{array}$ & Lineage \\
\hline PB2 & $1-2280$ & A/duck/Mongolia/520/2015(H1N1) & LC121393 & 99 & group III \\
\hline PB1 & $1-2274$ & A/duck/Mongolia/66/2015(H10N2) & LC108118 & 98 & group III \\
\hline PA & $1-2151$ & A/duck/Mongolia/66/2015(H10N2) & LC108119 & 99 & group III \\
\hline HA & $1-1701$ & A/duck/Hubei/ZYSYG15/2015(H6N2) & KY415608 & 98 & group III \\
\hline NP & $1-1497$ & A/wild bird/Korea/SK14/2014(H1N1) & KX066872 & 99 & group III \\
\hline NA & $1-1410$ & A/wild bird/Wuhan/WHHN16/2014(H1N1) & KU143337 & 99 & Eurasian \\
\hline M & $1-959$ & A/duck/Mongolia/543/2015(H4N6) & LC121415 & 99 & Europe \\
\hline NS & $1-838$ & A/duck/Mongolia/543/2015(H4N6) & LC121416 & 99 & Allele ॥ \\
\hline
\end{tabular}

\section{Molecular characterization of the ZJ-1664 and ZJ-1667 H6N1 strains}

Based on the deduced amino acid sequences of the HA proteins, the cleavage site pattern PQIETR/GL occurs in the HA from both the ZJ-1664 and ZJ-1667 H6N1 viruses. The presence of a monobasic cleavage site indicates that these strains are low pathogenic AIVs [44]. The amino acids at receptor binding sites were well conserved (Table 2). The receptor binding sites of ZJ-1664 and ZJ-1667, Q226 and G228 (H3 numbering), are similar to other H6 AIVs, suggesting that these strains may preferentially bind $\alpha-2,3$ linked sialic acid receptors, which are predominant in avian species [45]. The P186L, E (or D)190 V and G228S substitutions have been reported to favor the affinity of influenza viruses for human type receptors [21, 46]; these substitutions were not observed in ZJ-1664 or ZJ-1667, Additional file 1: Figure S1.

No substitutions associated with resistance to NA inhibitors (oseltamivir; His275Tyr substitution) or amantadines were observed in the NA [47] and M2 proteins (Val27Ala and Ser31Asn substitutions) [48] in ZJ-1664 or ZJ-1667. The PB2 protein substitution

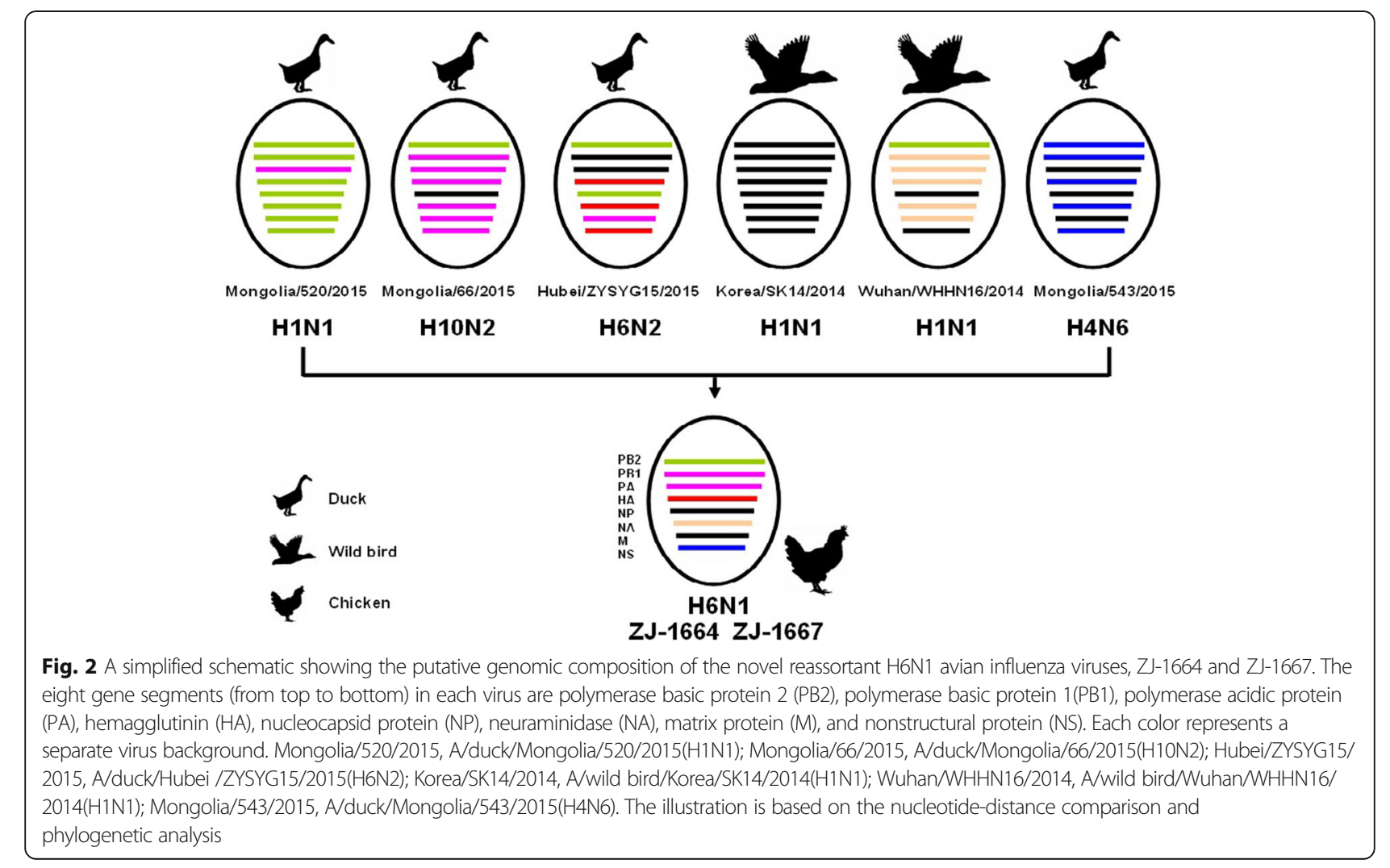


Table 2 Conservation analysis of amino acids at the cleavage site and receptor-binding sites in the HA protein of the ZJ-1664 and ZJ-1667 H6N1 strains and reference H6 viruses

\begin{tabular}{|c|c|c|c|c|c|c|c|c|c|c|c|}
\hline \multirow[t]{2}{*}{ H3 numbering system } & \multirow{2}{*}{$\begin{array}{l}\text { N-linked } \\
\text { glycosylation } \\
\text { sites in HA }\end{array}$} & \multirow{2}{*}{$\begin{array}{l}\text { HA } \\
\text { cleavage } \\
\text { 320-329 }\end{array}$} & \multicolumn{7}{|c|}{ Receptor-binding site } & \multirow{2}{*}{$\begin{array}{l}\text { Left edge of } \\
\text { receptor-binding } \\
\text { site } \\
\mathbf{2 2 0 - 2 2 9}\end{array}$} & \multirow{2}{*}{$\begin{array}{l}\text { Right edge of } \\
\text { receptor-binding } \\
\text { site } \\
\mathbf{1 3 4 - 1 3 8}\end{array}$} \\
\hline & & & 98 & 153 & 155 & 183 & 190 & 194 & 195 & & \\
\hline H6 position & & $339-344$ & 107 & 166 & 168 & 197 & 204 & 208 & 209 & $234-243$ & $146-150$ \\
\hline ZJ-1664(H6N1) & 5 & PQIETR & Y & W & I & $\mathrm{H}$ & $E$ & L & Y & RPAVNGQRGR & GVTKA \\
\hline ZJ-1667(H6N1) & 6 & PQIETR & Y & W & । & $\mathrm{H}$ & E & L & Y & RPAVNGQRGR & GVTKA \\
\hline A/chicken/Zhejiang/727031/2014(H6N2) & 5 & PQIETR & Y & W & V & $\mathrm{H}$ & E & L & Y & RPAVNGQRGR & GVSSA \\
\hline A/duck/Zhejiang/727038/2014(H6N2) & 6 & PQIETR & Y & W & 1 & $\mathrm{H}$ & E & L & Y & RPAVNAQRGR & GVSSA \\
\hline A/chicken/Zhejiang/727001/2014(H6N6) & 5 & PQIETR & Y & W & V & $\mathrm{H}$ & E & L & Y & RPAVNGQRGR & GVSSA \\
\hline A/chicken/Zhejiang/727028/2014(H6N6) & 6 & PQIETR & Y & W & I & $\mathrm{H}$ & E & L & Y & KPAVNGQRGR & GVSSA \\
\hline A/chicken/Zhejiang/110102/2015(H6N6) & 5 & PQIETR & Y & W & 1 & $\mathrm{H}$ & $\mathrm{E}$ & L & Y & RPVVNGQRGR & GVTSS \\
\hline A/duck/Hubei/ZYSYG15/2015(H6N2) & 6 & PQIETR & Y & W & 1 & $\mathrm{H}$ & E & L & Y & RPAVNGQRGR & GVTKA \\
\hline A/chicken/Hunan/S4191/2009(H6N2) & 5 & PQIETR & Y & W & $\mathbf{v}$ & $\mathrm{H}$ & E & L & Y & RPAVNGQRGR & GVSSA \\
\hline A/duck/Shantou/2195/2003(H6N2) & 6 & PQIETR & Y & W & I & $\mathrm{H}$ & E & L & Y & RPAVNGQRGR & GVSSA \\
\hline A/wild duck/Shantou/2853/2003(H6N2) & 5 & PQIETR & Y & W & I & $\mathrm{H}$ & E & L & Y & RPAVNGQRGR & GVTSS \\
\hline A/duck/Hunan/573/2002(H6N2) & 5 & PQIETR & Y & W & I & $\mathrm{H}$ & $\mathrm{E}$ & L & Y & RPAVNGQRGR & GVTKA \\
\hline A/duck/Eastern China/48/2010(H6N6) & 5 & PQIETR & Y & W & I & $\mathrm{H}$ & E & L & Y & RPAVNGQRGR & GVSSA \\
\hline A/duck/Jiangxi/5178/2007(H6N2) & 5 & PQIETR & Y & W & I & $\mathrm{H}$ & E & L & Y & RPAVNGQRGR & GVSSA \\
\hline A/duck/Zhejiang/S4204/2010(H6N6) & 5 & PQIETR & Y & W & । & $\mathrm{H}$ & E & L & Y & RPAVNGQRGR & GVSSA \\
\hline A/swine/Guangdong/K6/2010(H6N6) & 5 & PQIETR & Y & W & । & $\mathrm{H}$ & $\mathrm{E}$ & L & Y & RPVVNGQRSR & GVTSS \\
\hline A/muscovyduck/Vietnam/LBM601/2014(H6N6) & 5 & PQIETR & Y & W & । & $\mathrm{H}$ & E & L & Y & RPAVNGQRGR & GVSSA \\
\hline A/mallard/Ohio/664/2002(H6N6) & 5 & PQVKTR & Y & W & I & $\mathrm{H}$ & $E$ & L & Y & RPPANGQRGR & GVSSA \\
\hline A/Teal/Hong Kong/W312/97(H6N1) & 6 & PQIETR & Y & W & । & $\mathrm{H}$ & E & L & Y & RPAVNGQRGR & GTTRS \\
\hline A/Taiwan/2/2013(H6N1) & 6 & PQIATR & Y & W & V & $\mathrm{H}$ & V & L & Y & RPAVNGQRSR & GVTNA \\
\hline
\end{tabular}

Residues in bold indicate differences from the consensus alignment

Glu627Lys is associated with the pathogenicity of AIVs in mice [49], and the Thr271Ala substitution plays a key role in enhanced polymerase activity of influenza viruses in mammalian host cells [50]; neither of these substitutions was observed in the PB2 of ZJ-1664 or ZJ-1667.

\section{Prediction of glycosylation sites in the ZJ-1664 and ZJ- 1667 H6N1 strains}

$N$-linked glycosylation of HA is associated with virulence, alterations in HA antigenicity, and viral affinity for the influenza virus receptor [51, 52]. We predicted potential $N$-linked glycosylation sites in the HA and NA of the ZJ-1664 and ZJ-1667 strains by using the NetNGlyc 1.0 server, which predicted five (or six) potential $N$-linked glycosylation sites in HA (HA1, 27, (38), 182 and 306; HA2, 498 and 557, Table 2) and seven in NA $(50,58,63,68,88,146$, and 235). These H6N1 strains have different N-linked glycosylation sites in HA suggesting that they probably possess different biological characteristics.

\section{Receptor-binding analysis of the ZJ-1664 and ZJ-1667 H6N1 strains}

Receptor-binding specificity of HA is a key determinant for viral host range [53]. We analyzed the receptor-binding specificity of the H6N1 viruses using $\mathrm{HA}$ assays with sialidase-treated RBCs, which have only $\alpha-2,6$ receptor, normal chicken RBCs (containing both $\alpha-2,6$ and $\alpha-2,3$ receptors), and sheep RBCs (mainly expressing the $\alpha-2,3$ receptor). Analysis of the viral titers revealed that ZJ-1664 and ZJ-1667 agglutinated all three types of $\mathrm{RBCs}$, indicating that they possess specificity toward both the avian and human receptors (Table 3).

\section{Antigenic analysis of the ZJ-1664 and ZJ-1667 H6N1 strains}

Antigenic characterization is an important tool in the selection of strains to maintain updated influenza vaccinations [54]. To evaluate the antigenic characteristics of ZJ-1664 and ZJ-1667, we used the HI assay to compare cross-reactivity with other $\mathrm{H} 6$ viruses (H6N2 and H6N6), which were recently isolated from chickens and ducks in Zhejiang Province (Table 4). The ZJ-1664 and 
ZJ-1667 strains did not react well with the other Zhejiang H6N2 and H6N6 AIVs belonging to group II (HA gene).

\section{Viral growth kinetics}

The in vitro growth properties of the ZJ-1664 and ZJ-1667 viruses were characterized in MDCK and A549 cells. The growth curves in MDCK and A549 cells showed that both viruses reached a maximum at 48 postinoculation, and suggesting that they have good replication capacity in mammalian cells (Fig. 3).

\section{Pathogenicity in mice}

To evaluate the pathogenicity and replicative potential of the ZJ-1664 and ZJ-1667 viruses in mammalian hosts, $\mathrm{BALB} / \mathrm{c}$ mice were infected intranasally with $10^{6.0} \mathrm{EID}_{50}$ of each virus. The mice infected with these two viruses exhibited slight weight-loss (no significant difference) (Fig. 4). These H6N1 viruses were able to replicate without prior adaptation. Six days after inoculation, high titers of ZJ-1664 and ZJ-1667 were detected in the lungs of infected mice, and could not be detected in the brain, spleen, liver, or kidney of infected mice. Additionally, six days after inoculation ZJ-1664 could also be detected in cardiac tissue from infected mice. Survival rates 14-days post-inoculation were $100 \%$ (6/6; Table 5).

Histopathological analyses showed that 6 days postinoculation lung tissue had a light interstitial inflammatory hyperaemia (Fig. 5a). Immunohistochemistry was also performed to assess whether H6N1 viruses infected cells were present in tissues (including bronchial epithelial cells and alveolar epithelial cells) from infected mice 6 days post-inoculation (Fig. 5b). The H6N1 viruses were able to replicate in both bronchial epithelial cells and alveolar epithelial cells.

\section{Discussion}

In recent years, human infections with the $\mathrm{H} 5$ and $\mathrm{H} 9$ subtypes of AIVs have received considerable attention,
Table 4 Antigenic analysis of the ZJ-1664 and ZJ-1667 H6N1 influenza viruses according to the hemagglutination inhibition test

\begin{tabular}{lll}
\hline Polyclonal antisera titers to & \multicolumn{2}{l}{ Reassortant $\mathrm{H6N1}$ virus } \\
\cline { 2 - 3 } & ZJ-1664 & ZJ-1667 \\
\hline ZJ-1664(H6N1) & 256 & 256 \\
ZJ-1667(H6N1) & 256 & 256 \\
A/chicken/Zhejiang/727031/2014(H6N2) & 16 & 16 \\
A/duck/Zhejiang/727038/2014(H6N2) & 16 & 16 \\
A/chicken/Zhejiang/727001/2014(H6N6) & 32 & 32 \\
A/chicken/Zhejiang/727028/2014(H6N6) & 16 & 16 \\
A/chicken/Zhejiang/110102/2015(H6N6) & 16 & 16 \\
A/chicken/Zhejiang/C1/2013(H9N2) & 2 & 2 \\
A/goose/Zhejiang/112071/2014(H5N1) & 4 & 4 \\
\hline
\end{tabular}

and the H6 subtype of AIVs has gained little increase in awareness. In 1965, the H6 influenza viruses were first identified in turkeys in the United States; during the past 20 years, $\mathrm{H} 6$ viruses have become established in poultry populations across Asia and have been isolated from poultry worldwide $[14,16-18,26,55]$. In the United States, the zoonotic transmission of $\mathrm{H} 6$ viruses to humans has also been suggested by reports of significantly elevated titers of H6-specific antibodies among veterinarians routinely exposed to avian species [56]. A systematic serologic study showed that $0.4 \%$ serum specimens $(63 / 15,689)$ of workers in the poultry industry in mainland China were positive for the H6 virus [20]. Recently, H6 viruses have been detected in mammalian species, such as dogs and pigs, in Asian countries [23, 57]. Many previous studies have demonstrated that several subtypes of H6 influenza viruses (H6N1, H6N2, H6N5, H6N6 and H6N8) are cocirculated in domestic duck and chicken populations in China, which provide the opportunity for significant viral reassortment $[14,15,18,19,26,58,59]$. The prevalence of the H6 influenza viruses throughout the world, the ability of $\mathrm{H} 6$ strains to infect mammals, and the potential for

Table 3 Virus receptor binding specificity of the avian H6N1, avian H9N2 and human H1N1 influenza viruses

\begin{tabular}{|c|c|c|c|c|}
\hline Virus & $\begin{array}{l}\text { HA titers with normal } \\
\text { chicken } \mathrm{RBCs}\end{array}$ & $\begin{array}{l}\text { HA titers with } \\
\text { a-2,3 specific- } \\
\text { neuraminidase- } \\
\text { treated chicken RBCs }\end{array}$ & $\begin{array}{l}\text { HA titers with } \\
\text { sheep RBCs }\end{array}$ & Receptor specificity \\
\hline ZJ-1664(H6N1) & 256 & 32 & 256 & $\begin{array}{l}\text { a2,3-SA and a2, } \\
6-5 A \text { binding }\end{array}$ \\
\hline ZJ-1667(H6N1) & 256 & 32 & 256 & $\begin{array}{l}\text { a2,3-SA and a2, } \\
6-5 A \text { binding }\end{array}$ \\
\hline $\begin{array}{l}\text { A/chicken/Zhejiang/ } \\
\text { 329/2011(H9N2) }\end{array}$ & 256 & $<2$ & 256 & a2,3-SA binding \\
\hline $\begin{array}{l}\text { A/Puerto Rico/8/ } \\
\text { 1934(H1N1) }\end{array}$ & 256 & 256 & $<2$ & a2,6-SA binding \\
\hline
\end{tabular}

Note: The HA titer was defined as the reciprocal of the highest virus dilution resulting in the hemagglutination of RBCs. "a2,3-SA" and " $a 2,6-S A^{\prime \prime}$ indicate " $a-2,3-$ linked sialic acids" (avian receptor) and "a-2,6-linked sialic acids" (human receptor), respectively 

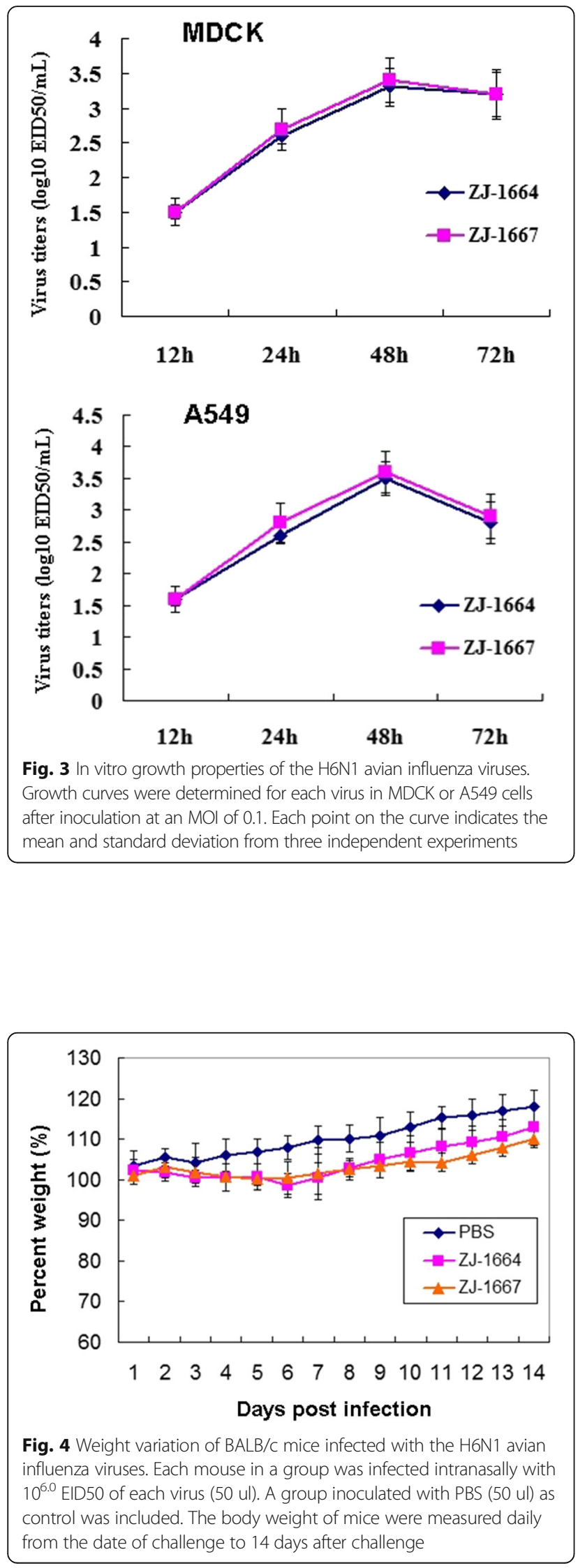

future reassortment and variation raises concern about the pandemic potential of $\mathrm{H} 6$ AIVs.

On 20 May 2013, the world's first human-infected case of H6N1 influenza viruses was reported in Taiwan [60]. Although Tzarum et al.'s research showed that this strain retained specificity for avian receptor [46], and demonstrates that the $\mathrm{H} 6$ viruses possess the ability to infect mammals [23, 24]. The persistent exposure of H6N1 viruses into human populations and the lack of pre-existing immunity to $\mathrm{H} 6$ viruses suggest the possible emergence of a pandemic human influenza virus $[16,17,22]$.

Mice are often used as a mammalian model to study the pathogenesis of influenza A viruses, including avian strains [61, 62]. Many studies have reported variable pathogenicity of H6 strains in mice [18, 19,63]. Specific amino acid substitutions in the PB2 (E627K), PA (T97I), and HA (N394 T) proteins of H6N1 viruses contribute to enhanced growth characteristics and altered cell tropism, and may also enhance the virulence H6N1 AIVs in mice $[64,65]$. We did not observe any of these specific substitutions in the ZJ-1664 or ZJ-1667 H6N1 strains. Our results indicate that these novel H6N1 AIVs possess specificity toward both the avian and human receptors, which are in agreement to the results of chicken H6N1 HA reported in previous studies [25, 66]; and while they did not cause lethal infections in mice, they are able to replicate in the lungs of the mice without prior adaptation. It has been reported that $34 \%$ of the $\mathrm{H} 6$ viruses coming from Chinese poultry are able to bind human type receptors, and some of these strains are able to transmit in guinea pigs through direct inoculation or contact [16]. The continued circulation of H6N1 viruses may represent a threat to human health.

Wild birds are a natural reservoir for AIVs; AIVs can replicate efficiently in their natural hosts, but replicate poorly in other species. H6 viruses are established in poultry populations throughout China, and domestic ducks are considered a population that can perpetuate most AIVs. Because infected ducks generally do not show obvious clinical symptoms, they can act as intermediate hosts between migratory birds and terrestrial poultry in the AIV ecosystem in China [14, 15, 67]. Terrestrial poultry (such as chickens) have molecular characteristics suitable to be intermediate hosts for transmission of AIVs to humans, and such transmission could generate new influenza viruses with pandemic potential [6-8].

\section{Conclusions}

In this study, we identified two novel H6N1 AIV strains, resulting from a reassortment event that occurred between the H6 AIV and other AIV subtypes, including the H10, H1, and H4 strains. Chickens from LPMs in Eastern China may play an important role in expanding 
Table 5 Mammalian viral replication of the novel reassortant H6N1 avian influenza viruses isolated from poultry in Eastern China, ZJ1664 and ZJ-1667

\begin{tabular}{|c|c|c|c|c|c|c|}
\hline \multirow[t]{2}{*}{ Virus } & \multirow{2}{*}{$\begin{array}{l}\text { No. of } \\
\text { survivors/ } \\
\text { no. } \\
\text { tested }\end{array}$} & \multirow[t]{2}{*}{$\begin{array}{l}\text { HI titer } \\
(\log 2)\end{array}$} & \multicolumn{4}{|c|}{$\begin{array}{l}\text { Virus replication in experimentally infected mice } \\
\text { Virus titers in organs of mice }\left(\log _{10} \mathrm{EID}_{50 / \mathrm{ml}}\right)\end{array}$} \\
\hline & & & Tissue & 3 day & 6 day & 9 day \\
\hline \multirow[t]{6}{*}{ ZJ-1664 } & $6 / 6$ & $6.33 \pm 0.52$ & Lung & $2.67 \pm 0.57$ & $3.67 \pm 0.57$ & $2.33 \pm 0.57$ \\
\hline & & & Brain & 0 & 0 & 0 \\
\hline & & & Heart & 0 & $1.33 \pm 0.57$ & 0 \\
\hline & & & Liver & 0 & 0 & 0 \\
\hline & & & Kidney & 0 & 0 & 0 \\
\hline & & & Spleen & 0 & 0 & 0 \\
\hline \multirow[t]{6}{*}{ ZJ-1667 } & $6 / 6$ & $5.83 \pm 0.75$ & Lung & $2.33 \pm 0.57$ & $2.67 \pm 0.57$ & $1.33 \pm 0.57$ \\
\hline & & & Brain & 0 & 0 & 0 \\
\hline & & & Heart & 0 & 0 & 0 \\
\hline & & & Liver & 0 & 0 & 0 \\
\hline & & & Kidney & 0 & 0 & 0 \\
\hline & & & Spleen & 0 & 0 & 0 \\
\hline
\end{tabular}

Fifteen mice were intranasaly inoculated with $10^{6.0}$ EID50 of the H6N1 virus in a 0.05 -ml volume of PBS. Six mice were observed for survival for 14 days. The remaining nine mice from each experimental group were exsanguinated on day 3, 6 and 9, and lungs, brains, hearts, kidneys, spleens, and livers were collected for virus titration in embryonated chicken eggs by the method of Reed and Muench. Sera were harvested at 14 days after infection from the six remaining mice. Seroconversion was confirmed by the hemagglutination inhibition $(\mathrm{HI})$ test. Data represent mean \pm SD

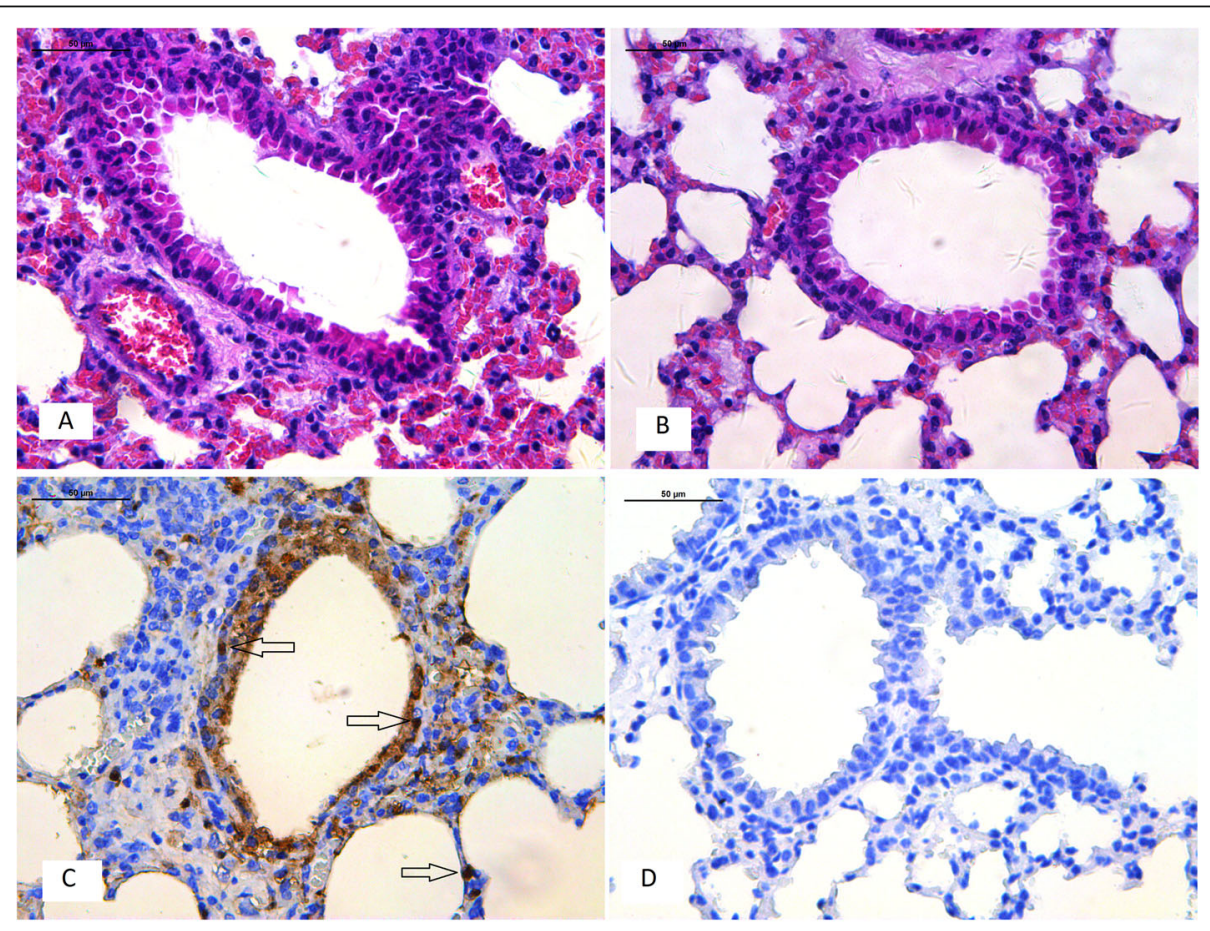

Fig. 5 Histology and immunohistochemistry of mice infected with ZJ-1664 at 6 days post-infection. Histology of lung sections stained by hematoxylin and eosin from inoculated mice (a) or negative control (b). Immunohistochemical detection of virus nucleoprotein in lungs from inoculated mice (c) or negative control (d). Arrows indicate positively stained lung alveolar epithelial cells 
the host range for AIVs. These strains were able to replicate in mice without prior adaptation. Considering that the reassorted H6N1 viruses were isolated from chickens in this study, it is possible that chickens play an important role as a permissive host in the reassortment of novel H6N1 AIVs. These results indicate continual reassortment between AIVs from different avian species, and continued circulation of these viruses may pose a potential threat to humans.

\section{Additional file}

Additional file 1: Figure S1. Comparison of deduced HA amino acid sequences of $\mathrm{H} 6$ viruses using the BioEdit program. The P186L, E190V and $\mathrm{G} 228 \mathrm{~S}$ substitutions (H3 numbering system) are shown in boxes. (JPG $241 \mathrm{~kb})$

\section{Abbreviations}

AIVs: Avian influenza viruses; EID50: 50\% embryo infectious dose; HA: Hemagglutinin; LPMs: Live poultry markets; M: Matrix protein; MOI: Multiplicity of infection; NA: Neuraminidase; NP: Nucleocapsid protein; NS: Nonstructural protein; PA: Polymerase acidic protein; PB1: Polymerase basic protein 1; PB2: Polymerase basic protein 2; RBCs: Red blood cells

\section{Acknowledgements}

We would like to thank the native English speaking scientists of Elixigen Company (Huntington Beach, California) for editing our manuscript.

\section{Funding}

This work was supported by grants from the National Science Foundation of the People's Republic of China (81502852), Zhejiang Provincial Natural Science Foundation of China (Y19H260021 and Y15H190006), and the Independent Task of State Key Laboratory for Diagnosis and Treatment of Infectious Diseases (Nos. $2017 Z Z 10$ and 2018ZZ06).

\section{Authors' contributions}

HW and NW conceived and designed the assays. HW, FY, FL, RL, XP, BC, and HY conducted experimental work. HW and NW analysed the data and wrote the paper. All authors read and approved the final manuscript.

\section{Ethics approval}

The animal experiments conducted in this study were approved by the First Affiliated Hospital, School of Medicine, Zhejiang University (No. 2015-15).

\section{Consent for publication}

Not applicable.

\section{Competing interests}

The authors declare that they have no competing interests.

\section{Publisher's Note}

Springer Nature remains neutral with regard to jurisdictional claims in published maps and institutional affiliations.

\section{Author details}

${ }^{1}$ State Key Laboratory for Diagnosis and Treatment of Infectious Diseases, Collaborative Innovation Center for Diagnosis and Treatment of Infectious Diseases, the First Affiliated Hospital, School of Medicine, Zhejiang University, 79 Qingchun Road, Zhejiang 310003, Hangzhou, China. ${ }^{2}$ Department of Emergency, The First Affiliated Hospital of Zhejiang Chinese Medical University, Hangzhou, China.
Received: 21 March 2018 Accepted: 25 September 2018

Published online: 24 October 2018

\section{References}

1. Zhu X, Yu W, McBride R, Li Y, Chen LM, Donis RO, Tong S, Paulson JC, Wilson IA. Hemagglutinin homologue from H17N10 bat influenza virus exhibits divergent receptor-binding and $\mathrm{pH}$-dependent fusion activities. Proc Natl Acad Sci U S A. 2013;110:1458-63.

2. Tong $S$, Zhu $X$, Li Y, Shi M, Zhang J, Bourgeois $M$, Yang H, Chen $X$, Recuenco S, Gomez J, et al. New world bats harbor diverse influenza a viruses. PLoS Pathog. 2013:9:e1003657.

3. Kawaoka Y, Chambers TM, Sladen WL, Webster RG. Is the gene pool of influenza viruses in shorebirds and gulls different from that in wild ducks? Virology. 1988;163:247-50.

4. Liu M, He S, Walker D, Zhou N, Perez DR, Mo B, Li F, Huang X, Webster RG, Webby RJ. The influenza virus gene pool in a poultry market in south Central China. Virology. 2003;305:267-75.

5. Cardona $\mathrm{C}$, Yee $\mathrm{K}$, Carpenter $\mathrm{T}$. Are live bird markets reservoirs of avian influenza? Poult Sci. 2009;88:856-9.

6. Xu KM, Li KS, Smith GJ, Li JW, Tai H, Zhang JX, Webster RG, Peiris JS, Chen $\mathrm{H}$, Guan Y. Evolution and molecular epidemiology of H9N2 influenza a viruses from quail in southern China, 2000 to 2005. J Virol. 2007:81:2635-45.

7. Guo YJ, Krauss S, Senne DA, Mo IP, Lo KS, Xiong XP, Norwood M, Shortridge KF, Webster RG, Guan Y. Characterization of the pathogenicity of members of the newly established H9N2 influenza virus lineages in Asia. Virology. 2000;267:279-88.

8. Gambaryan AS, Tuzikov AB, Pazynina GV, Desheva JA, Bovin NV, Matrosovich MN, Klimov Al. 6-sulfo sialyl Lewis $X$ is the common receptor determinant recognized by $\mathrm{H} 5, \mathrm{H} 6, \mathrm{H} 7$ and $\mathrm{H} 9$ influenza viruses of terrestrial poultry. Virol J. 2008:5:85.

9. Munster VJ, Baas C, Lexmond P, Waldenstrom J, Wallensten A, Fransson T, Rimmelzwaan GF, Beyer WE, Schutten M, Olsen B, et al. Spatial, temporal, and species variation in prevalence of influenza a viruses in wild migratory birds. PLoS Pathog. 2007;3:e61

10. Krauss S, Obert CA, Franks J, Walker D, Jones K, Seiler P, Niles L, Pryor SP, Obenauer JC, Naeve CW, et al. Influenza in migratory birds and evidence of limited intercontinental virus exchange. PLoS Pathog. 2007:3:e167.

11. Krauss S, Walker D, Pryor SP, Niles L, Chenghong L, Hinshaw VS, Webster RG. Influenza a viruses of migrating wild aquatic birds in North America. Vector Borne Zoonotic Dis. 2004;4:177-89.

12. Kim HR, Lee YJ, Lee KK, Oem JK, Kim SH, Lee MH, Lee OS, Park CK. Genetic relatedness of $\mathrm{H} 6$ subtype avian influenza viruses isolated from wild birds and domestic ducks in Korea and their pathogenicity in animals. J Gen Virol. 2010;91:208-19.

13. Nam JH, Kim EH, Song D, Choi YK, Kim JK, Poo H. Emergence of mammalian species-infectious and -pathogenic avian influenza H6N5 virus with no evidence of adaptation. J Virol. 2011;85:13271-7.

14. Huang K, Zhu H, Fan X, Wang J, Cheung CL, Duan L, Hong W, Liu Y, Li L, Smith DK, et al. Establishment and lineage replacement of $\mathrm{H} 6$ influenza viruses in domestic ducks in southern China. J Virol. 2012;86:6075-83.

15. Zhao G, Lu X, Gu X, Zhao K, Song Q, Pan J, Xu Q, Duan Z, Peng D, Hu S, et al. Molecular evolution of the $\mathrm{H} 6$ subtype influenza a viruses from poultry in eastern China from 2002 to 2010. Virol J. 2011;8:470.

16. Wang G, Deng G, Shi J, Luo W, Zhang G, Zhang Q, Liu L, Jiang Y, Li C, Sriwilaijaroen $\mathrm{N}$, et al. $\mathrm{H} 6$ influenza viruses pose a potential threat to human health. J Virol. 2014:88:3953-64.

17. Chin PS, Hoffmann E, Webby R, Webster RG, Guan Y, Peiris M, Shortridge KF. Molecular evolution of $\mathrm{H} 6$ influenza viruses from poultry in southeastern China: prevalence of $\mathrm{H} 6 \mathrm{~N} 1$ influenza viruses possessing seven a/Hong Kong/156/97 (H5N1)-like genes in poultry. J Virol. 2002;76:507-16.

18. Wu H, Peng $X$, Cheng L, Wu N. Molecular characterization of novel reassortant $\mathrm{H} 6 \mathrm{~N} 2$ subtype avian influenza viruses isolated from poultry in eastern China, in 2014. Infect Genet Evol. 2015;36:41-5.

19. Wu H, Lu R, Peng $X$, Cheng L, Jin C, Lu X, Xie T, Yao H, Wu N. Isolation and genetic characterization of novel reassortant H6N6 subtype avian influenza viruses isolated from chickens in eastern China. Arch Virol. 2016;161:1859-72

20. Xin L, Bai T, Zhou JF, Chen YK, Li XD, Zhu WF, Li Y, Tang J, Chen T, Qin K, et al. Seropositivity for avian influenza $\mathrm{H} 6$ virus among humans, China. Emerg Infect Dis. 2015;21:1267-9. 
21. Wei SH, Yang JR, Wu HS, Chang MC, Lin JS, Lin CY, Liu YL, Lo YC, Yang CH, Chuang $\mathrm{JH}$, et al. Human infection with avian influenza a H6N1 virus: an epidemiological analysis. Lancet Respir Med. 2013;1:771-8.

22. Shi W, Shi Y, Wu Y, Liu D, Gao GF. Origin and molecular characterization of the human-infecting H6N1 influenza virus in Taiwan. Protein Cell. 2013;4:846-53.

23. Lin $H T$, Wang $C H$, Chueh $L L$, Su BL, Wang LC. Influenza $A(H 6 N 1)$ Virus in Dogs, Taiwan. Emerg Infect Dis. 2015;21:2154-7.

24. Cheng K, Yu Z, Gao Y, Xia X, He H, Hua Y, Chai H. Experimental infection of dogs with H6N1 avian influenza a virus. Arch Virol. 2014;159:2275-82.

25. Wang F, Qi J, Bi Y, Zhang W, Wang M, Zhang B, Liu J, Yan J, Shi Y, Gao GF. Adaptation of avian influenza a (H6N1) virus from avian to human receptorbinding preference. EMBO J. 2015;34:1661-73.

26. Huang K, Bahl J, Fan XH, Vijaykrishna D, Cheung CL, Webby RJ, Webster RG, Chen H, Smith GJ, Peiris JS, Guan Y. Establishment of an H6N2 influenza virus lineage in domestic ducks in southern China. J Virol. 2010;84:6978-86.

27. Wu HB, Guo CT, Lu RF, Xu LH, Wo EK, You JB, Wang YT, Wang QG, Wu NP. Genetic characterization of subtype $\mathrm{H} 1$ avian influenza viruses isolated from live poultry markets in Zhejiang Province, China, in 2011. Virus Genes. 2012; 44:441-9.

28. Wu H, Lu R, Peng X, Cheng L, Liu F, Wu N. Characterization of novel Reassortant influenza a (H5N2) viruses isolated from poultry in eastern China, 2015. Front Microbiol. 2017:8:741.

29. Hoffmann E, Stech J, Guan Y, Webster RG, Perez DR. Universal primer set for the full-length amplification of all influenza a viruses. Arch Virol. 2001;146: 2275-89.

30. Tamura K, Stecher G, Peterson D, Filipski A, Kumar S. MEGA6: molecular evolutionary genetics analysis version 6.0. Mol Biol Evol. 2013;30:2725-9.

31. Gupta R JEaBS: Prediction of N-glycosylation sites in human proteins; 2004 Database: NetNGlyc 1.0 [Internet]. 2004.

32. Tewawong N, Prachayangprecha S, Vichiwattana P, Korkong S, Klinfueng S, Vongpunsawad S, Thongmee T, Theamboonlers A, Poovorawan Y. Assessing antigenic drift of seasonal influenza a(H3N2) and a(H1N1)pdm09 viruses. PLoS One. 2015;10:e0139958.

33. Zou S, Gao R, Zhang Y, Li X, Chen W, Bai T, Dong L, Wang D, Shu Y. Molecular characterization of $\mathrm{H} 6$ subtype influenza viruses in southern China from 2009 to 2011. Emerg Microbes Infect. 2016;5:e73.

34. Suptawiwat $O$, Kongchanagul A, Chan-It W, Thitithanyanont A, Wiriyarat W, Chaichuen K, Songserm T, Suzuki Y, Puthavathana P, Auewarakul P. A simple screening assay for receptor switching of avian influenza viruses. J Clin Virol. 2008:42:186-9.

35. Medeiros R, Escriou N, Naffakh N, Manuguerra JC, van der Werf S. Hemagglutinin residues of recent human a $(\mathrm{H} 3 \mathrm{~N} 2)$ influenza viruses that contribute to the inability to agglutinate chicken erythrocytes. Virology. 2001;289:74-85

36. Liu Q, Zhou B, Ma W, Bawa B, Ma J, Wang W, Lang Y, Lyoo Y, Halpin RA, Lin $X$, et al. Analysis of recombinant H7N9 wild-type and mutant viruses in pigs shows that the Q226L mutation in HA is important for transmission. J Virol. 2014:88:8153-65

37. Jin H, Wang D, Sun J, Cui Y, Chen G, Zhang X, Zhang J, Li X, Chai H, Gao Y, et al. Pathogenesis and phylogenetic analyses of two avian influenza H7N1 viruses isolated from wild birds. Front Microbiol. 2016;7:1066.

38. Chang H, Dai F, Liu Z, Yuan F, Zhao S, Xiang X, Zou F, Zeng B, Fan Y, Duan G. Seroprevalence survey of avian influenza a $(\mathrm{H} 5)$ in wild migratory birds in Yunnan Province, southwestern China. Virol J. 2014;11:18.

39. Tan L, Su S, Smith DK, He S, Zheng Y, Shao Z, Ma J, Zhu H, Zhang G. A combination of HA and PA mutations enhances virulence in a mouseadapted H6N6 influenza a virus. J Virol. 2014;88:14116-25.

40. Wang J, Sun Y, Xu Q, Tan Y, Pu J, Yang H, Brown EG, Liu J. Mouse-adapted H9N2 influenza a virus PB2 protein M147L and E627K mutations are critical for high virulence. PLoS One. 2012;7:e40752.

41. Wu H, Peng X, Lu R, Xu L, Liu F, Cheng L, Lu X, Yao H, Wu N. Virulence of an H5N8 highly pathogenic avian influenza is enhanced by the amino acid substitutions PB2 E627K and HA A149V. Infect Genet Evol. 2017;54:347-54.

42. Reed $\mathrm{L}$, Muench $\mathrm{H}$. A simple method for estimating fifty percent endpoints. Am J Hyg. 1938;27:493-7.

43. Wu H, Peng X, Cheng L, Lu X, Jin C, Xie T, Yao H, Wu N. Genetic and molecular characterization of H9N2 and $\mathrm{H} 5$ avian influenza viruses from live poultry markets in Zhejiang Province, Eastern China. Sci Rep. 2015:5:17508.

44. Horimoto T, Ito T, Alexander DJ, Kawaoka Y. Cleavability of hemagglutinin from an extremely virulent strain of avian influenza virus containing a unique cleavage site sequence. J Vet Med Sci. 1995;57:927-30.
45. Matrosovich MN, Gambaryan AS, Teneberg S, Piskarev VE, Yamnikova SS, Lvov DK, Robertson JS, Karlsson KA. Avian influenza a viruses differ from human viruses by recognition of sialyloligosaccharides and gangliosides and by a higher conservation of the HA receptor-binding site. Virology. 1997;233:224-34.

46. Tzarum N, de Vries RP, Zhu X, Yu W, McBride R, Paulson JC, Wilson IA. Structure and receptor binding of the hemagglutinin from a human H6N1 influenza virus. Cell Host Microbe. 2015;17:369-76.

47. Aoki FY, Boivin G, Roberts N. Influenza virus susceptibility and resistance to oseltamivir. Antivir Ther. 2007;12:603-16.

48. Deyde VM, Xu X, Bright RA, Shaw M, Smith CB, Zhang Y, Shu Y, Gubareva LV, Cox NJ, Klimov Al. Surveillance of resistance to adamantanes among influenza a(H3N2) and a(H1N1) viruses isolated worldwide. J Infect Dis. 2007;196:249-57.

49. Schat KA, Bingham J, Butler JM, Chen LM, Lowther S, Crowley TM, Moore RJ, Donis RO, Lowenthal JW. Role of position 627 of PB2 and the multibasic cleavage site of the hemagglutinin in the virulence of H5N1 avian influenza virus in chickens and ducks. PLoS One. 2012;7:e30960.

50. Bussey KA, Bousse TL, Desmet EA, Kim B, Takimoto T. PB2 residue 271 plays a key role in enhanced polymerase activity of influenza a viruses in mammalian host cells. J Virol. 2010;84:4395-406.

51. Zhang Y, Zhu J, Li Y, Bradley KC, Cao J, Chen H, Jin M, Zhou H. Glycosylation on hemagglutinin affects the virulence and pathogenicity of pandemic H1N1/2009 influenza a virus in mice. PLoS One. 2013;8:e61397.

52. Suptawiwat O, Boonarkart C, Chakritbudsabong W, Uiprasertkul M, Puthavathana P, Wiriyarat W, Auewarakul P. The N-linked glycosylation site at position 158 on the head of hemagglutinin and the virulence of H5N1 avian influenza virus in mice. Arch Virol. 2015;160:409-15.

53. Xiong $X$, McCauley JW, Steinhauer DA. Receptor binding properties of the influenza virus hemagglutinin as a determinant of host range. Curr Top Microbiol Immunol. 2014;385:63-91.

54. Klimov A, Balish A, Veguilla V, Sun H, Schiffer J, Lu X, Katz JM, Hancock K. Influenza virus titration, antigenic characterization, and serological methods for antibody detection. Methods Mol Biol. 2012;865:25-51.

55. Hotta K, Takakuwa H, Le QM, Phuong SL, Murase T, Ono E, Ito T, Otsuki K, Yamashiro T. Isolation and characterization of H6N1 and H9N2 avian influenza viruses from ducks in Hanoi, Vietnam. Virus Res. 2012;163:448-53.

56. Myers KP, Setterquist SF, Capuano AW, Gray GC. Infection due to 3 avian influenza subtypes in United States veterinarians. Clin Infect Dis. 2007;45:4-9.

57. Zhang G, Kong W, Qi W, Long LP, Cao Z, Huang L, Qi H, Cao N, Wang W, Zhao $\mathrm{F}$, et al. Identification of an H6N6 swine influenza virus in southern China. Infect Genet Evol. 2011;11:1174-7.

58. Yuan R, Zou L, Kang Y, Wu J, Zeng X, Lu J, Liang L, Song Y, Zhang X, Ni H et al. Reassortment of avian influenza a/H6N6 viruses from live poultry Markets in Guangdong, China. Front Microbiol. 2016;7:65.

59. Xie Z, Xie L, Zhou C, Liu J, Pang Y, Deng X, Fan Q. Complete genome sequence analysis of an $\mathrm{H} 6 \mathrm{~N} 1$ avian influenza virus isolated from Guangxi pockmark ducks. J Virol. 2012;86:13868-9.

60. Yuan J, Zhang L, Kan X, Jiang L, Yang J, Guo Z, Ren Q. Origin and molecular characteristics of a novel 2013 avian influenza a(H6N1) virus causing human infection in Taiwan. Clin Infect Dis. 2013:57:1367-8.

61. Belser JA, Gustin KM, Pearce MB, Maines TR, Zeng H, Pappas C, Sun X, Carney PJ, Villanueva JM, Stevens J, et al. Pathogenesis and transmission of avian influenza a (H7N9) virus in ferrets and mice. Nature. 2013:501:556-9.

62. Brown EG. Increased virulence of a mouse-adapted variant of influenza a/ FM/1/47 virus is controlled by mutations in genome segments $4,5,7$, and 8. J Virol. 1990;64:4523-33.

63. Yao $Y$, Wang $H$, Chen $Q$, Zhang $H$, Zhang $T$, Chen J, Xu B, Sun B, Chen Z. Characterization of low-pathogenic H6N6 avian influenza viruses in Central China. Arch Virol. 2013;158:367-77.

64. Yu Z, Cheng K, Xin Y, Sun W, Li X, Huang J, Zhang K, Yang S, Wang T, Zheng $X$, et al. Multiple amino acid substitutions involved in the adaptation of H6N1 avian influenza virus in mice. Vet Microbiol. 2014;174:316-21.

65. Cheng K, Yu Z, Chai H, Sun W, Xin Y, Zhang Q, Huang J, Zhang K, Li X, Yang S, et al. PB2-E627K and PA-T97I substitutions enhance polymerase activity and confer a virulent phenotype to an $\mathrm{H} 6 \mathrm{~N} 1$ avian influenza virus in mice. Virology. 2014;468-470:207-13.

66. Ni F, Kondrashkina E, Wang Q. Structural and functional studies of influenza virus a/H6 hemagglutinin. PLoS One. 2015;10:e0134576.

67. Cheung CL, Vijaykrishna D, Smith GJ, Fan XH, Zhang JX, Bahl J, Duan L, Huang K, Tai H, Wang J, et al. Establishment of influenza a virus (H6N1) in minor poultry species in southern China. J Virol. 2007;81:10402-12. 